\title{
HPLC-DAD-ESI/MS ANALYSIS OF ARNICA TM CONSTITUENTS
}

\author{
KATARZYNA KIMEL, SYLWIA GODLEWSKA, \\ MIROSŁAWA KRAUZE-BARANOWSKA* and LORETTA POBŁOCKA-OLECH
}

\author{
Department of Pharmacognosy with Medicinal Plants Garden, \\ Medical University of Gdańsk, Poland
}

\begin{abstract}
The herbal drugs obtained from Arnica montana flowers are known for their anti-inflammatory activity. However, there is no detailed data on chemical constituents of the whole Arnica plant. HPLC-DAD-ESI/MS analysis of the whole Arnica montana plant (Arnica TM), used in the preparation of allopathic and homeopathic medicinal products, has been conducted. The qualitative and quantitative analysis comprised phenolic acids, flavonoids and sesquiterpene lactones - helenalin and dihydrohelenalin esters identified earlier in Arnica flowers. The analyzed material showed to be a rich source of caffeoylquinic acid (CQA) derivatives, especially 3,5di-O-caffeoylquinic acid. According to the literature data, the anti-inflammatory activity of extracts from the whole Arnica montana plant can be due to CQA presence as dominating compounds.
\end{abstract}

Keywords: polyphenols, Arnica, sesquiterpene lactones, simple phenols

Arnica flowers have been known for centuries as a herbal remedy, originally applied in phytotherapy internally $(1,2)$, and currently only externally (1-4). In many in vitro, in vivo and clinical studies, their anti-inflammatory activity has been confirmed, mainly due to the sesquiterpene lactone - helenalin, present in free form as well as ester derivatives (3, 5-15). The sesquiterpene lactones of arnica inhibit the synthesis of prostaglandins by inactivating the prostaglandin synthetase enzyme and cause a decrease in the biochemical parameters associated with inflammatory processes $(3,5-11)$. The mechanism of action at the molecular level of helenalin comprises the inhibition of activation of transcription factors such as NF- $\chi \mathrm{B}$, NF-AT stimulating the transcription of pro-inflammatory proteins, among others, cytokines IL- 1 , IL- 8 , TNF- $\alpha$, acute phase proteins, COX, and iNO- synthetase (7, 9-11).

The chemical composition of arnica flowers is complex and includes, in addition to sesquiterpene lactones (12-15) also flavonoids (14-18) and phenolic acids (19-21), in particular derivatives of caffeoylquinic acids (CAQs) $(20,21)$. The role of the latter compounds in the biological activity of arnica flowers is not fully recognized. Some mono- $C Q A$ isomers have an affinity to protect against $\mathrm{H}_{2} \mathrm{O}_{2}$ induced apoptosis in PC12 cells by suppressing the mitochondrial membrane depolarization caused by oxidative stress (22). Additionally, it was reported that 5-CQA and cynarin had a protective effect against t-BOOH-induced ROS generation in HepG2 cells (23). It was also stated, that 5-CQA prevents inflammatory responses in IL-1â-stimulated human SW-1353 chondrocytes, a model for osteoarthritis $(24,25)$. Arnica flower flavonoids are involved in the anti-inflammatory action of this plant raw material, inhibiting the activity of pro-inflammatory mediators COX, 5-LOX, and hyaluronidase and elastase enzymes $(8,10)$.

Literature data on the chemical composition of the Arnica montana includes mainly information on the chemical constituents of dried $(13-15,18)$ or fresh flowers (12), In addition, the composition of sesquiterpene lactones in the leaves (26) was recognized, and phenolic acid complex and essential oil constituents were studied in the roots (27). There is no detailed data on the active compounds of the whole plant as raw plant material for the preparation of medicinal products - allopathic or homeopathic. In very large dilutions, tincture or liquid arnica extracts are used internally in homeopathy (3). Nowadays, the basic tools in the study of the composition of biologically active compounds in plants are hyphenated techniques, mainly high-performance liquid chromatography coupling with selective detectors DAD and MS (28).

* Corresponding author: e-mail: krauze@gumed.edu.pl 
The aim of the study was to analyze by use of HPLC-DAD-ESI/MS elaborated methods the chemical composition of the extract from fresh whole Arnica montana L. plant prepared according to the homeopathic procedure (tincture mother TM).

\section{MATERIALS AND METHODS}

\section{Chemicals and reagents}

Standard compounds of apigenin, kaempferol, quercetin, isoquercetin, hyperoside, chlorogenic acid, caffeic acid, ferulic acid were obtained from Fluka (St. Gallen, Switzerland). Luteolin 7-O-glucoside, apigenin 7-O-glucoside, luteolin, astragalin, galangin, tectochrysin, genkwanin, isorhamnetin, quercetin 3-glucuronide, kaempferol 3-O-glucuronide from Extrasynthèse (Lyon, France). Hispidulin, pectolinaringenin were obtained from PhytoLab (Vestenbergsgreuth, Germany). Naringenin, isochlorogenic acid and p-coumaric acid were obtained from Koch-Light (Colnbrook, Great Britain). Chrysin and vanillic acid were obtained from Sigma-Aldrich (Saint Louis, USA). Helenalin was purchased from Abcam (Cambridge, Great Britain). Cynarin originated from the standard collection of the Department of Pharmacognosy of the Medical University of Gdańsk (Poland). Analyticalgrade chloroform and methanol were obtained from POCH S.A. (Gliwice, Poland). Analytical-grade formic acid (89-91\% purity) was purchased from Merck (Darmstadt, Germany). HPLC-grade acetonitrile (LC/MS) Lichrosolv was purchased from Sigma-Aldrich (Steinheim, Germany). Demineralized water was prepared by using Millipore Water Purification System (Molsheim, France).

\section{Plant material and sample preparation}

Arnica TM (series M6100663) was obtained from Boiron (France). Arnica TM tincture was pre- pared from fresh Arnica montana L. plants (whole plants and parts of its roots) in proportion $1: 10$ (raw plant material : $96 \%$ ethanol). The water content in collected fresh plant material was $75.4 \%$. Arnica plants were selected by qualified botanists and harvesters. Harvesting is regulated and confined to several mountainous regions in France (Vosges, Alps, Massif Central, Pyrenees, etc.) and Germany (Hesse, Bavaria). It takes place at the beginning of the flowering season in June or July depending on the altitude. The samples of Arnica TM were prepared by evaporating the solvent from a volume of 1 $\mathrm{mL}$ of the tincture and then dissolving the dry residue in $1 \mathrm{~mL}$ of methanol. The methanol solution was filtered through membrane filter prior to chromatographic analysis.

\section{LC system}

HPLC analysis was performed using an LC system by Shimadzu (Kyoto, Japan) consisting of two pumps LC-20AD, semi-micro mixer, CBM20A system controller, CT0-20AC column thermostat, SIL $20 \mathrm{AC}_{\mathrm{XR}}$ autosampler, UV-vis detector (Diode Array Detector) SPD-M20A, LCMS-2020 mass spectrometer with ESI ionization. Data were acquired and processed by LabSolution software.

\section{HPLC-DAD analysis of simple phenols and polyphenols}

Separation was carried out on a Kinetex C-PFP column $(2.6 \mu \mathrm{m}, 4.6 \times 100 \mathrm{~mm})$ (Phenomenex, USA), using gradient elution according to the pro$\operatorname{gram} \mathrm{I}(\% \mathrm{~B}$ in $\mathrm{A}): \mathrm{A}-\mathrm{H}_{2} \mathrm{O}: \mathrm{HCOOH} 100: 0.1$ $(v / v), \mathrm{B}-\mathrm{CAN}: \mathrm{H}_{2} \mathrm{O}: \mathrm{HCOOH} 50: 50: 0.1(v / v / v)$ : $0 \min -12 \% \mathrm{~B}, 10 \min -20 \% \mathrm{~B}, 35 \min -43 \% \mathrm{~B}$, $60 \min -100 \%$ B, $64 \min -100 \%$ B, 66 min $-12 \%$ $\mathrm{B}, 76 \mathrm{~min}-12 \% \mathrm{~B}$ at flow rate of mobile phase 0.8 $\mathrm{mL} / \mathrm{min}$, column temperature $-20^{\circ} \mathrm{C}$, injection volume: $1 \mu \mathrm{L}$ (qualitative analysis), $6 \mu \mathrm{L}$ and $1 \mu \mathrm{L}$ of

Table 1. Validation parameters for HPLC determination of phenolic acids, flavonoids and sesquiterpene lactones in Arnica TM tincture.

\begin{tabular}{|c|c|c|c|c|c|}
\hline $\begin{array}{c}\text { Chemical } \\
\text { compound }\end{array}$ & $\begin{array}{c}\text { Range } \\
\mu \mathrm{g} / \mathrm{mL}\end{array}$ & $\begin{array}{c}\text { Calibration } \\
\text { curve }\end{array}$ & $\begin{array}{c}\mathrm{LOD} \\
{[\mu \mathrm{g} / \mathrm{mL}]}\end{array}$ & $\begin{array}{c}\mathrm{LOQ} \\
{[\mu \mathrm{g} / \mathrm{mL}]}\end{array}$ \\
\hline \multirow{3}{*}{ Chlorogenic acid } & $6.25-100$ & $\mathrm{y}=2043.5 \mathrm{x}+354.75$ & 0.9993 & \\
& $100-400$ & $\mathrm{y}=1559.3 \mathrm{x}+50603$ & 0.9992 & 0.702 \\
0.9907 & $\mathrm{y}=2580.5 \mathrm{x}-306286$ & 0.9989 & 2.757 & 9.191 \\
\hline Luteolin & $3.125-100$ & $\mathrm{y}=1525.3 \mathrm{x}-4222$ & 0.9997 & 0.372 & 1.240 \\
\hline Quercetin & $3.125-100$ & $\mathrm{y}=5029.6 \mathrm{x}-6925.1$ & 0.9982 & 0.638 & 2.126 \\
\hline Helenalin* & $3.125-100$ & $\mathrm{y}=3256.4 \mathrm{x}+12005$ & 0.9989 & 1.267 & 4.223 \\
\hline
\end{tabular}

* HPLC determination of helenalin and dihydrohelenalin esters; ** HPLC determination of helenalin 

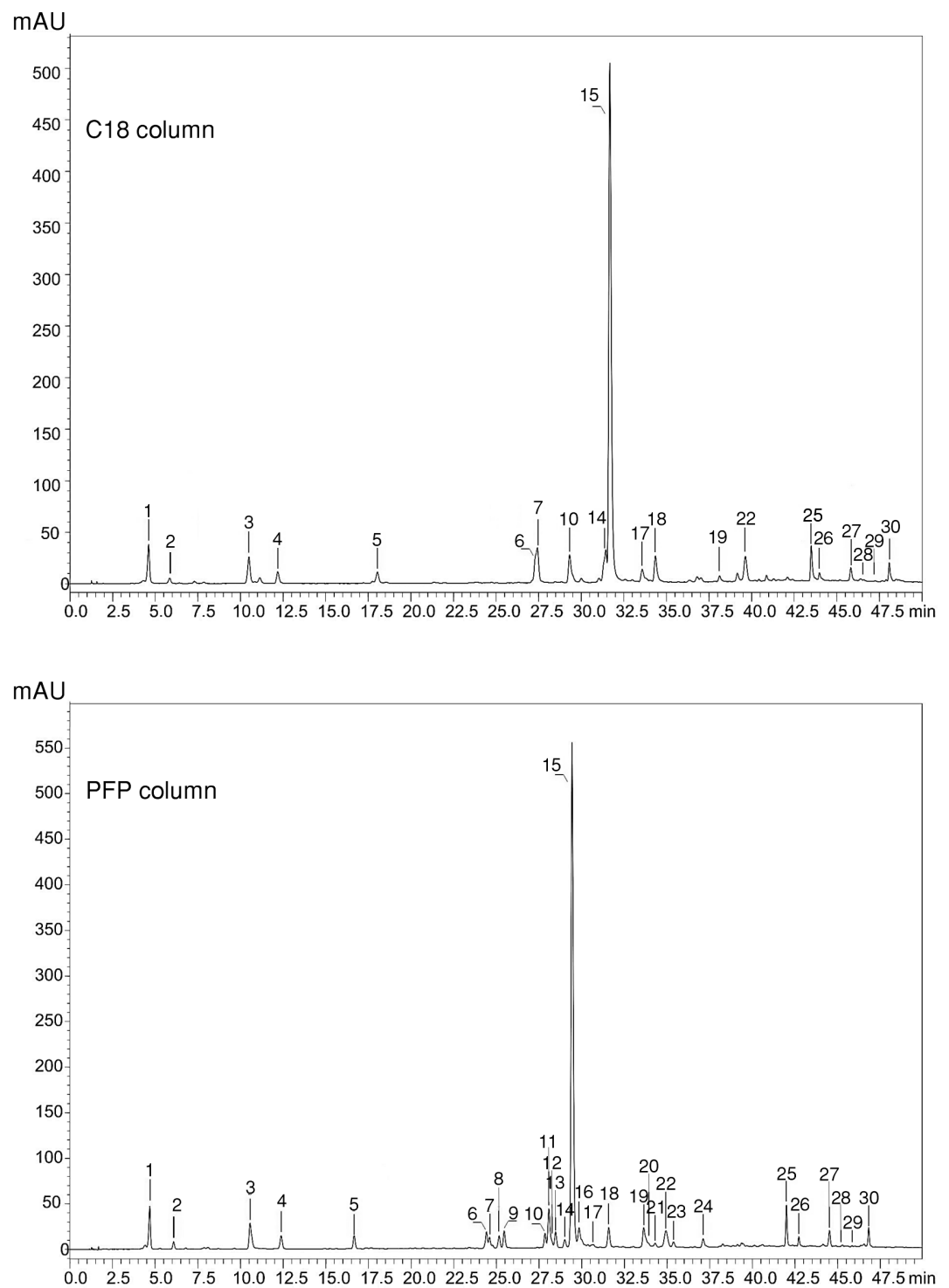

Figure 1. HPLC separation of Arnica TM tincture: Kinetex C-18 and Kinetex PFP columns using gradient program I, UV $\lambda$-330 nm.

tincture diluted with methanol in proportion $1: 4$ (quantitative analysis). UV detection at $\lambda-330 \mathrm{~nm}$.

\section{HPLC-DAD analysis of sesquiterpene lactones. Helenalin}

The analysis was carried out on a Kinetex C-18 column $(2.6 \mu \mathrm{m}, 4.6 \times 100 \mathrm{~mm})$ (Phenomenex, USA) using a gradient elution according to the program II (\% D in C): $\mathrm{C}-\mathrm{H}_{2} \mathrm{O}: \mathrm{MeOH} 45: 5(v / v)$, D - MeOH: $0 \mathrm{~min}-17 \%$ D, $20 \mathrm{~min}-17 \%$ D, $25 \mathrm{~min}$ - $100 \%$ D, 35 min - 100\% D, 40 min - 17\% D, 55 min $-17 \% \mathrm{D}$ at flow rate of mobile phase 0.8 $\mathrm{mL} / \mathrm{min}$, column temperature $-30^{\circ} \mathrm{C}$, injection volume: $3 \mu \mathrm{L}$, UV detection at $\lambda-225 \mathrm{~nm}$.

\section{Helenalin and dihydrohelenalin esters}

The analysis was carried out on two Kinetex C18 columns $(2.6 \mu \mathrm{m}, 4.6 \times 100 \mathrm{~mm})$ connected in series using a gradient elution according to the program III : $\mathrm{C}-\mathrm{H}_{2} \mathrm{O}: \mathrm{MeOH} 50: 50(v / v), \mathrm{D}-\mathrm{MeOH}$ $0 \mathrm{~min}-0 \% \mathrm{D}, 51 \mathrm{~min}-100 \% \mathrm{D}, 70 \mathrm{~min}-100 \% \mathrm{D}$, $71 \mathrm{~min}-85 \% \mathrm{D}$ at a mobile phase flow rate of 0.8 $\mathrm{mL} / \mathrm{min}$, column temperature $30^{\circ} \mathrm{C}$ and $\mathrm{UV}$ detection $\lambda-225 \mathrm{~nm}$. The injection volume was $6 \mu \mathrm{L}$.

\section{ESI-MS conditions}

Mass spectra were acquired operating in positive (PI) ion modes. A full scan (range $m / z$ 150-800 for simple phenols and polyphenols, $m / z$ 250-400 
for sesquiterpene lactones) and SIM (selected ion monitoring) techniques were used for monitoring specific signals. Operating parameters: interface voltage $5.0 \mathrm{kV}$, detector voltage $1.25 \mathrm{kV}$, heat block $200^{\circ} \mathrm{C}$, DL temperature $250^{\circ} \mathrm{C}$, nebulizing gas flow $\left(\mathrm{N}_{2}\right) 1.5 \mathrm{~L} / \mathrm{min}$, drying gas flow $15 \mathrm{~L} / \mathrm{min}$.

\section{Quantitative analysis and method validation}

The HPLC methods developed for the purposes of quantitative analysis were validated by determining calibration curves, linear regression, limit of quantitation (LOQ), limit of detection (LOD), repeatability and recovery of the analyzed compounds, which were estimated according to Food and Drug Administration, Center for Drug Evaluation and Research Guidelines (29). Calibration curves were determined for the standard compounds. Linearity for the working concentrations of the standard compounds was evaluated by determining the correlation coefficient. Stock solutions of standard compounds were diluted in methanol $(1 \mathrm{mg} / \mathrm{mL})$ and the regression curves were determined basing on the analysis of plot of peak area for a concentration of compounds from $1 \mathrm{mg} / \mathrm{mL}$ to $3.125 \mu \mathrm{g} / \mathrm{mL}$. LOQ and LOD were determined as the concentration of the standard compound equaling $10 \times$ and $3 \times$ of the signal-to-noise ratio, respectively. Calibration curves, correlation coefficients, LOQ and LOD values are presented in Table 1.

The intra- and inter-day repeatability of the methods developed were evaluated by analyzing continuous injections of the same sample six times per day and once per day for six consecutive days respectively, and determined according to the relative standard deviation (RSD). The intra-day precision of simple phenols and polyphenols determination ranged from 0.28 to $5.05 \%$, and the inter-day precision from 0.76 to $5.35 \%$. The intra-day precision of helenalin determination was $2.68 \%$ and the inter-day precision was $6.11 \%$. The intra-day precision of helenalin and dihydrohelenalin esters determination was $2.83 \%$ and the inter-day precision was $8.97 \%$. Recovery was determined by adding known amount of standard compound corresponding to $25 \%$ and $50 \%$ (helenalin) and 75\%, 125\% (selected simple phenols and polyphenols standards) of its concentration in the sample, and calculating the percentage of recovery from the median sum of compound in the plant material as well as the added quantities of standard compound. The recovery for the helenalin was 90.2 to $96.2 \%$ and for simple phenols and polyphenols ranged from 92.3 to $112.2 \%$.

\section{RESULTS}

In the preliminary chromatographic experiments, HPLC separation conditions were optimized dependently on a group of analyzed secondary metabolites by selection of two types of columns, namely Kinetex C-18 column $(2.6 \mu \mathrm{m}, 4.6 \times 100$ $\mathrm{mm}$ and $2.6 \mu \mathrm{m}, 2.1 \times 100 \mathrm{~mm})$ and Kinetex PFP column (2.6 $\mu \mathrm{m}, 4.6 \times 100 \mathrm{~mm})$ (Fig. 1). A number of mobile phases containing a mixture of $\mathrm{H}_{2} \mathrm{O}$ : CAN : $\mathrm{HCOOH}$ and $\mathrm{H}_{2} \mathrm{O}: \mathrm{ACN}$ or $\mathrm{H}_{2} \mathrm{O}: \mathrm{MeOH}$

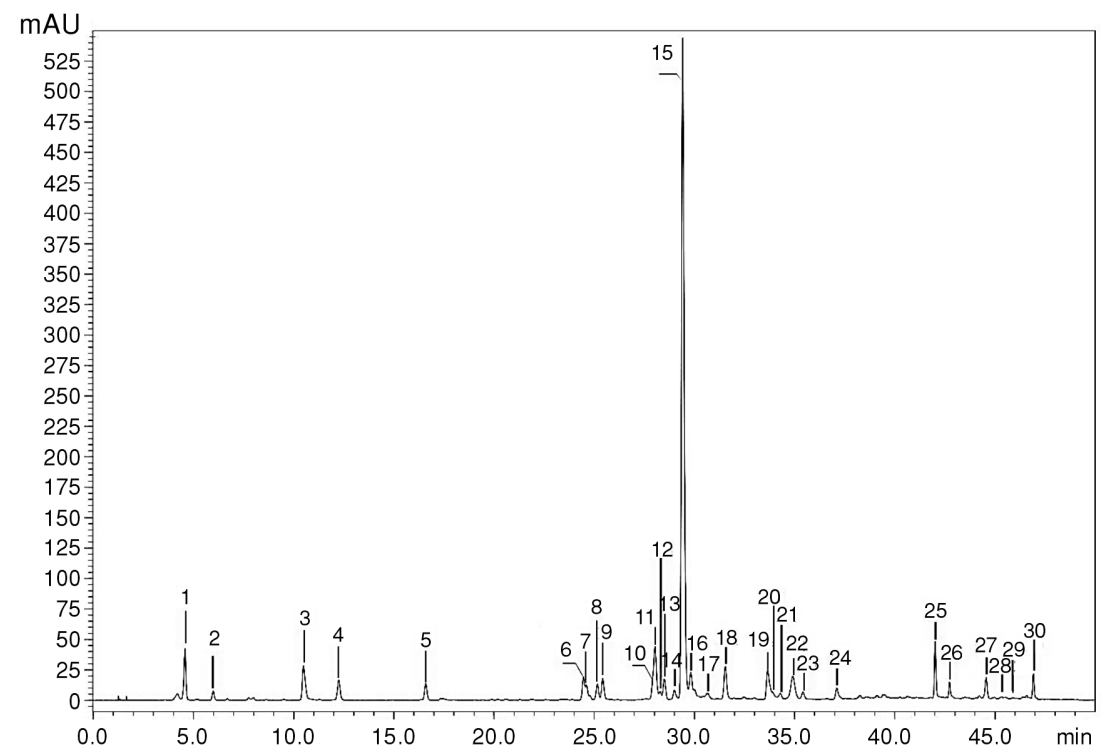

Figure 2. Chromatograms HPLC of Arnica TM tincture: Kinetex PFP column $(2.6 \mu \mathrm{m}, 4.6 \times 100 \mathrm{~mm})$, gradient program I, UV $\lambda$-330 nm. 
Table 2. Polyphenols and simple phenols identified by HPLC-DAD-ESI/MS Arnica TM tincture (Boiron): Kinetex C-PFP column (2.6 $\mu$ m, $4.6 \times 100 \mathrm{~mm}$ ), gradient program I, UV $\lambda-330 \mathrm{~nm}$.

\begin{tabular}{|c|c|c|c|c|c|c|c|c|}
\hline $\begin{array}{c}\text { Peak } \\
\text { number }\end{array}$ & Compound & $\mathrm{t}_{\mathrm{R}}(\min )$ & & & $\begin{array}{l}\lambda_{\max } \\
1)\end{array}$ & & $\begin{array}{c}\text { ESI-MS } \\
(\mathrm{m} / \mathrm{z}) \\
{[\mathrm{M}+\mathrm{H}]^{+},}\end{array}$ & $\begin{array}{c}\text { Correlation } \\
\text { with } \\
\text { standard }\end{array}$ \\
\hline 1 & Isomer of caffeoylquinic acid & 4.6 & 234 & $243 \mathrm{sh}$ & $296 \mathrm{sh}$ & 326 & 355 & \\
\hline 2 & $\begin{array}{l}\text { 3,4-dihydrobenzoic acid } \\
\text { (protocatechic acid) }\end{array}$ & 6.0 & 259 & 292 & & & 155 & 0.8591 \\
\hline 3 & $\begin{array}{l}\text { 5- } O \text {-caffeyloquinic acid } \\
\text { (chlorogenic acid) }\end{array}$ & 10.5 & 234 & $243 \mathrm{sh}$ & $296 \mathrm{sh}$ & 324 & 355 & 0.943 \\
\hline 4 & Caffeic acid & 12.2 & 232 & $241 \mathrm{sh}$ & $294 \mathrm{sh}$ & 322 & 181 & 0.9981 \\
\hline 5 & $\begin{array}{l}1,3 \text {-di- } O \text {-caffeoylquinic } \\
\text { acid (cynarin) }\end{array}$ & 16.6 & 230 & $243 \mathrm{sh}$ & 299sh & 325 & 517 & 0.9813 \\
\hline 6 & Patuletin 3-O-glucoside & 24.5 & 256 & $269 \mathrm{sh}$ & 348 & & 495,333 & \\
\hline 7 & Patuletin 3-O-glucuronide & 24.7 & 256 & $267 \mathrm{sh}$ & 347 & & 509,333 & \\
\hline 8 & $\begin{array}{l}\text { Quercetin-3-O-glucoside } \\
\text { (isoquercetin) }\end{array}$ & 25.2 & 255 & $265 \mathrm{sh}$ & $310 \mathrm{sh}$ & 352 & 465 & 0.9813 \\
\hline 9 & Quercetin 3-O-glucuronide & 25.5 & 255 & $264 \mathrm{sh}$ & $310 \mathrm{sh}$ & 353 & 479 & \\
\hline 10 & Eupafolin 7-O-glucoside & 27.8 & 269 & $296 \mathrm{sh}$ & 330 & & 479,317 & \\
\hline 11 & Isomer of dicaffeoylquinic acid & 28.1 & 234 & $246 \mathrm{sh}$ & $298 \mathrm{sh}$ & 325 & 517 & \\
\hline 12 & Eupafolin 7-O-glucuronide & 28.3 & 269 & 334 & & & 493,317 & \\
\hline 13 & Kaempferol 3-O-glucoside & 28.6 & 264 & $300 \mathrm{sh}$ & 340 & & 449 & 0.9953 \\
\hline 14 & Kaempferol 3-O-glucuronide & 29.1 & 260 & $300 \mathrm{sh}$ & 347 & & 463 & \\
\hline 15 & 3,5-di- $O$-caffeoylquinic acid & 29.5 & 234 & $246 \mathrm{sh}$ & $296 \mathrm{sh}$ & 328 & 517 & \\
\hline 16 & 1,5-di- $O$-caffeoylquinic acid & 29.9 & 235 & $246 \mathrm{sh}$ & $296 \mathrm{sh}$ & 329 & 517 & \\
\hline 17 & 4,5-di- $O$-caffeoylquinic acid & 30.7 & 235 & $265 \mathrm{sh}$ & $300 \mathrm{sh}$ & 352 & 517 & \\
\hline 18 & $\begin{array}{l}\text { 1-methoxyoxaloyl-3,5-di- } O \text { - } \\
\text { caffeoylquinic acid }\end{array}$ & 31.6 & 235 & $241 \mathrm{sh}$ & $298 \mathrm{sh}$ & 329 & 603 & \\
\hline 19 & $\begin{array}{l}\text { Isomer of di- } O \text {-caffeoylquinic } \\
\text { acid }\end{array}$ & 33.7 & 235 & $242 \mathrm{sh}$ & $297 \mathrm{sh}$ & 328 & 517 & \\
\hline 20 & Luteolin 3'-O-glucoside & 34.0 & 267 & $301 \mathrm{sh}$ & 331 & & 449,317 & \\
\hline 21 & $\begin{array}{l}\text { Isomer of di- } O \text {-caffeoylquinic } \\
\text { acid }\end{array}$ & 34.4 & 230 & $240 \mathrm{sh}$ & $297 \mathrm{sh}$ & 330 & & \\
\hline 22 & Kaempferol 3-O-acetylglucoside & 35.0 & 264 & 300sh & 345 & & 491 & \\
\hline 23 & Derivative of caffeic acid & 35.5 & 232 & $245 \mathrm{sh}$ & $300 \mathrm{sh}$ & 330 & & \\
\hline 24 & Tricaffeoylquinic acid & 37.2 & 233 & $242 \mathrm{sh}$ & $300 \mathrm{sh}$ & 325 & 679 & \\
\hline 25 & Derivative of caffeic acid & 42.1 & 232 & $243 \mathrm{sh}$ & 300 sh & 329 & & \\
\hline 26 & Derivative of caffeic acid & 42.8 & 233 & $245 \mathrm{sh}$ & $300 \mathrm{sh}$ & 329 & & \\
\hline 27 & 6-Methoxyapigenin & 44.6 & 272 & & & 333 & 317 & \\
\hline 28 & Apigenin & 45.3 & 267 & $304 \mathrm{sh}$ & 329 & & 271 & 0.9231 \\
\hline 29 & Kaempferol & 45.9 & $253 \mathrm{sh}$ & $267 \mathrm{sh}$ & 299sh & 341 & 287 & 0.9231 \\
\hline 30 & Derivative of caffeic acid & 47.0 & 235 & $241 \mathrm{sh}$ & $307 \mathrm{sh}$ & 330 & & \\
\hline
\end{tabular}

were evaluated. Kinetex PFP column and gradient program I comprising an increasing concentration of CAN : $\mathrm{H}_{2} \mathrm{O}: \mathrm{HCOOH}$ in $\mathrm{H}_{2} \mathrm{O}: \mathrm{HCOOH}$ from $12 \%$ to $100 \%$ within $\mathrm{t}_{\mathrm{G}} 60$ min was selected as providing the best separation of polyphenols and simple phenols present in Arnica TM tincture (Figs. 1 and 2).
For separation of triterpene lactones shown to be the most effective Kinetex C-18 column (2.6 um, $4.6 \times$ $100 \mathrm{~mm}$ ) and two elution programs characterizing by an increase of concentrations of $\mathrm{MeOH}$ in a mixture of $\mathrm{H}_{2} \mathrm{O}: \mathrm{MeOH}(50: 50(v / v)$ - program II or $45: 5(v / v)$ - program III) (Figs. 3 and 4$)$. 
The results of qualitative and quantitative analyzes obtained under the conditions of developed HPLC-DAD-ESI/MS methods are presented in Tables 2-5. Compounds were identified according to the obtained DAD and ESI spectral data, by comparison with authentic standards $\left(\mathrm{t}_{\mathrm{R}}\right.$ value $)$ and literature data $(14-19,30)$

Identification of simple phenols and polyphenols

In the examined plant material, based on the number of separated peaks, 30 compounds were identified as belonging to simple phenols and polyphenols (Fig. 2 and Table 2). The analyses were carried out using 9 standard compounds from the group of phenolic acids: derivatives of benzoic acid: p-hydroxybenzoic, protocatechuic, gallic and vanillic; cinnamic acid derivatives: ferulic and caffeic, phenolic acids of an ester nature, namely: caffeic acid esters of quinic acid (CQA): chlorogenic acid (5-O-CQA), cynarin (1,3-O-CQA), isochlorogenic; and flavonoid compounds: from the group of flavones: luteolin, luteolin 7-O-glucoside, apigenin, apigenin 7-O-glucoside and from the group of flavonols: kaempferol, astragalin (kaempferol 3-O-
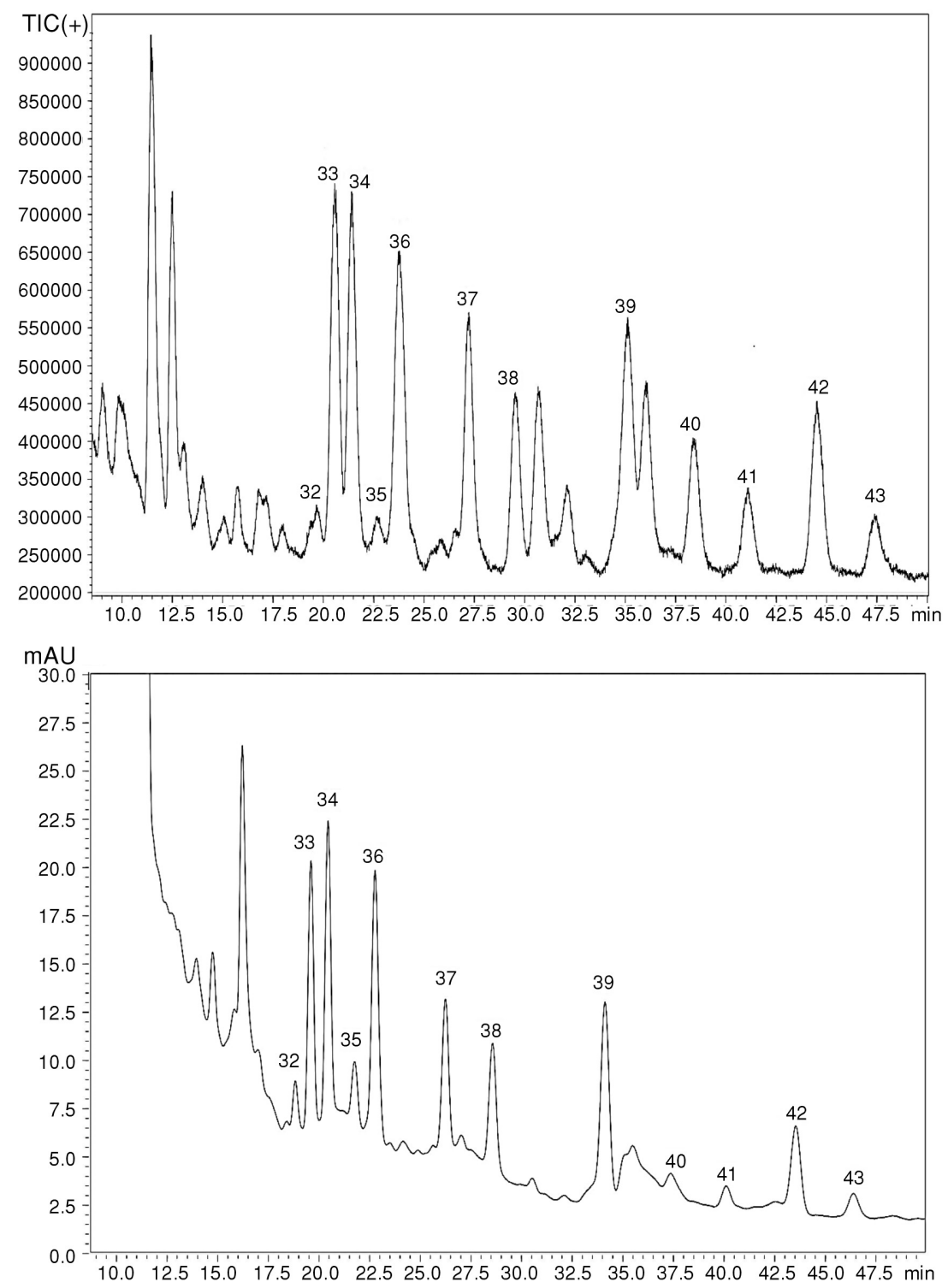

Figure 3. Chromatogram HPLC - TIC (+) and UV of sesquiterpene lactones (42-53) from Arnica TM tincture: Kinetex C-18 column (2.6 $\mu \mathrm{m}, 4.6 \times 100 \mathrm{~mm})$, gradient program III, UV $\lambda-225 \mathrm{~nm}$. 

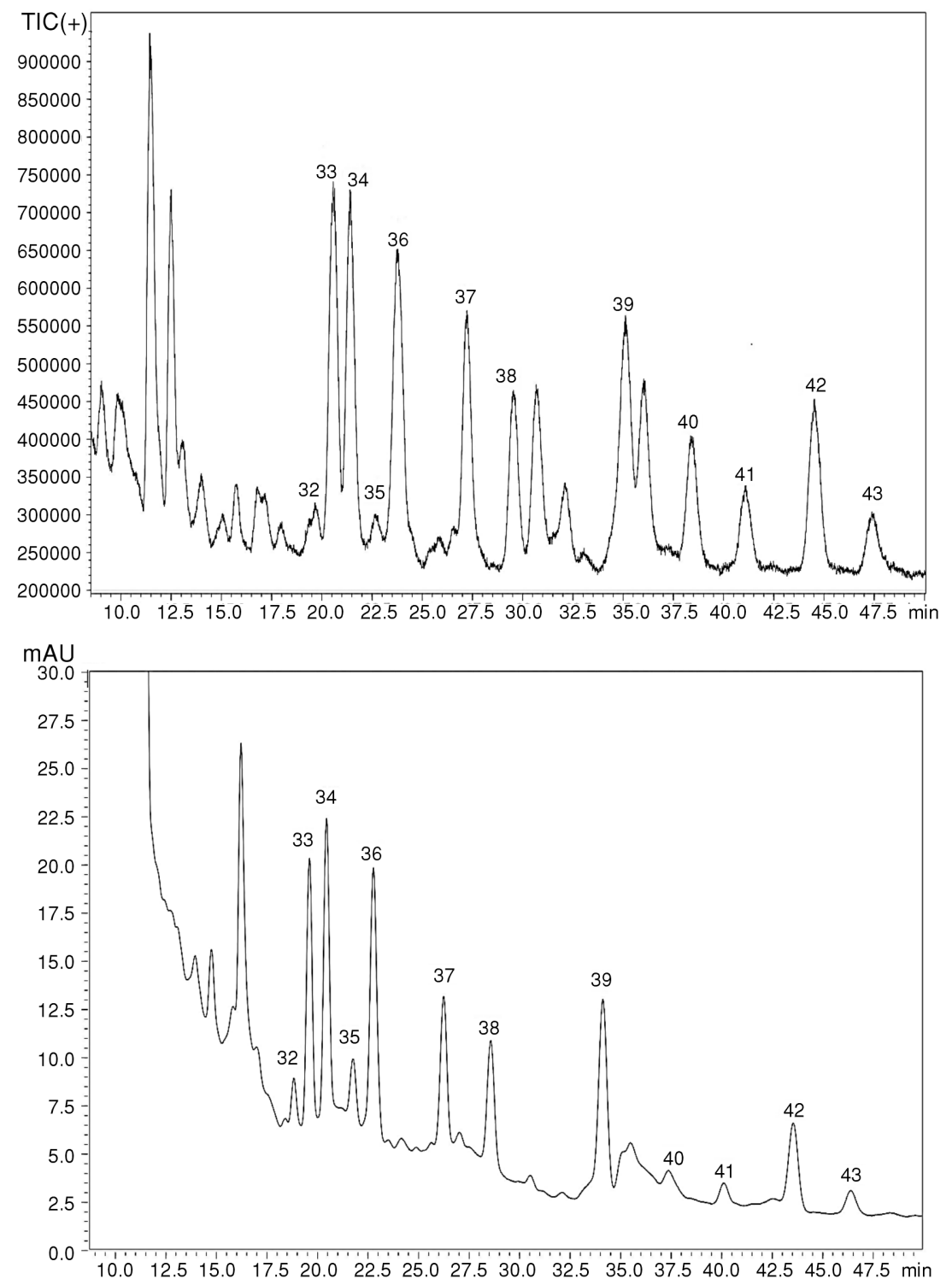

Figure 4. Chromatograms HPLC of Arnica TM tincture (A) and helenalin standard (C) and UV spectra of helenalin in Arnica TM - 31 (B) and helenalin standard $-\mathrm{S}$ (D): Kinetex C-18 column $(2.6 \mu \mathrm{m}, 4.6 \times 100 \mathrm{~mm})$, gradient program II, UV $\lambda-225 \mathrm{~nm}$.

glucoside), hyperoside (quercetin 3-O-galactoside), quercetin, isoquercetin (quercetin-3-O-glucoside) and isorhamnetin. Among the used standard compounds in Arnica TM tincture, the presence of cinnamic acid derivatives was confirmed: chlorogenic acid (compound 3), caffeic acid (4), cynarin (5), benzoic acid derivatives: protocatechuic acid (2), from the flavone group: apigenin (28), flavonols: isoquercetin (8), kaempferol 3-O-glucoside (13), kaempferol (29) (Table 2). These compounds have been previously identified in Arnica montana and Arnica chamissonis flowers (14-19, 30). However, the presence of the following compounds from the group of phenolic acids and from the flavonol deriv- atives, has not been confirmed in the analyzed material, namely: gallic acid, ferulic acid, p-hydroxybenzoic acid, p-coumaric acid, vanillic acid and apigenin 7-O-glucoside, quercetin, luteolin, luteolin 7$O$-glucoside, isorhamnetin and hyperoside $(15,18)$.

\section{Identification of flavonoids}

Using DAD and MS detectors based on a comparison of literature data $(16,17,30)$ and UV spectra obtained and $m / z$ values of molecular $[\mathrm{M}+\mathrm{H}]^{+}$ and fragmentation $[\mathrm{Ag}+\mathrm{H}]^{+}$ions in ESI spectra, in the tested plant material confirmed the presence of a number of flavones (Table 2), namely: eupafolin 7 $O$-glucoside (6-methoxyluteolin 7-O-glucoside) 
(10) (16) and luteolin 3'- $O$-glucoside (20) (16). In the flavonols group based on UV spectra and $\mathrm{m} / \mathrm{z}$ values of molecular ions, the following flavonols were identified: quercetin 3-O-glucuronide (9), kaempferol 3-O-glucuronide (14) (30) and kaempferol 3-O-acetylglucoside (22) (17). Compounds 6 and 7 are recognized as patuletin 3-O-glycosides $(17,30)$. The UV spectra of both compounds 6 and 7 were identical, which indicates the same glycosidation position in the flavonoid structure $\left(\lambda_{\max } 256\right.$, $269 \mathrm{sh}, 347 \mathrm{~nm}$ ). The ESI-MS spectra of both compounds showed the presence of fragmentation ion $[\mathrm{Ag}+\mathrm{H}]^{+}$at $\mathrm{m} / \mathrm{z} 333$ corresponding to the molecular weight of the patuletin (6-methoxyquercetin). In addition, the ESI-MS spectra of compounds 6 and 7 showed the presence of molecular ions $[\mathrm{M}+\mathrm{H}]^{+}$at $\mathrm{m} / \mathrm{z} 495$ for $\mathbf{6}$ and $\mathrm{m} / \mathrm{z} 509$ for $\mathbf{7}$, indicating that they are glycosidic forms of patuletin, respectively 3-O glucoside patuletin and 3-O-glucuronide patuletin. Both compounds have previously been identified in the species A. montana and A. chamissonis by Merfort et al. (16, 30). The UV spectrum of compound 9 shows the absorption maxima characteristic of quercetin derivatives (31). The UV spectrum of 9 is identical to the spectra of $\mathbf{8}$ identified as isoquercetin (quercetin 3-O-glucoside). Based on the presence of the molecular ion at $m / z 479$, compound 9 was recognized as quercetin 3-O-glucuronide (30). Compound $\mathbf{1 0}$ was tentatively identified as eupafolin 7-O-glucoside (7-O-glucoside 6-methoxyluteolin) taking into consideration the presence of two maxima of absorption in UV spectrum: at 330 $\mathrm{nm}$ (I maximum), $269 \mathrm{~nm}$ (II maximum) with an shoulder at $296 \mathrm{~nm}$, as specific for flavone with an ortho-dihydroxy group in the side phenyl (31), and observing the presence at $\mathrm{m} / \mathrm{z} 479$ and $\mathrm{m} / \mathrm{z} 317$ molecular $[\mathrm{M}+\mathrm{H}]^{+}$and fragmentation $[\mathrm{Ag}+\mathrm{H}]^{+}$ions, respectively. Until now, the eupafolin 7-O-glucoside ester form, namely 6"'-O-(2-methylbutyryl)-7$O$-glucoside eupafolin has been only demonstrated in A. chamissonis flowers $(17,30)$.

Compound 22 exhibited UV spectra similar to the UV spectrum of kaempferol 3-O-glucoside (13). The presence of the molecular ion $[\mathrm{M}+\mathrm{H}]^{+}$at $\mathrm{m} / \mathrm{z}$ 491 indicated that in the structure of the compound is acetylglucose. Based on this data, 22 was recognized as kaempferol 3-acetylglucoside, which was previously isolated only from Arnica chamissonis flowers (16). In contrast, kaempferol 3-O-glucuronide (14) identified in Arnica TM, was earlier described both in flowers of $A$. chamissonis and $A$. montana $(16,18)$. As with glucuronides and glucosides of patuletin and quercetin, also the retention time of kaempferol 3-O-glucuronide $\left(\mathrm{t}_{\mathrm{R}}-29.07\right.$ min) was higher compared to the kaempferol 3-Oglucoside $\left(t_{R}-28.56 \mathrm{~min}\right)$ (Table 2).

The UV spectrum of compound 20 indicates the absence of an ortho-dihydroxy group in the side phenyl, whereas the ESI-MS spectrum has a fragmentation ion $[\mathrm{Ag}+\mathrm{H}]^{+}$at $\mathrm{m} / \mathrm{z} 317$ and molecular ion $[\mathrm{M}+\mathrm{H}]^{+}$at $m / z 449$, what may indicate that this compound is a derivative of luteolin with attached sugar unit - glucose at C-3'-OH. Based on this, the compound was tentatively identified as luteolin 3 '- $O$ -

Table 3. Sesquiterpene lactones identified by HPLC-DAD-ESI/MS Arnica TM tincture (Boiron): Kinetex C-18 column $(2.6 \mu \mathrm{m}, 4.6 \times 100$ $\mathrm{mm}$ ), gradient program II, UV $\lambda-225 \mathrm{~nm}$ (compound 31$)$, Kinetex C-18 column (2.6 $\mu \mathrm{m}, 4.6 \times 100 \mathrm{~mm})$, gradient program III, UV $\lambda-225$ $\mathrm{nm}$ (compounds 32-43).

\begin{tabular}{|c|c|c|c|c|}
\hline Peak number & $\mathrm{t}_{\mathrm{R}}(\min )$ & $\mathrm{UV} \lambda_{\max }(\mathrm{nm})$ & {$[\mathrm{M}+\mathrm{H}]^{+/}[\mathrm{M}+\mathrm{Na}]^{+}$} & Compound \\
\hline 31 & 17.3 & 219 & 263 & Helenalin* \\
\hline 32 & 18.8 & 210 & 351 & Unknown lactone \\
\hline 33 & 19.6 & 212 & 371 & $11 \alpha, 13$-dihydro-2- $O$-tigloylflorilenalin \\
\hline 34 & 20.4 & 219 & $307 /-$ & Acetyl-dihydrohelenalin \\
\hline 35 & 21.8 & 221 & $385 /-$ & Unknown lactone \\
\hline 36 & 22.8 & 214 & $369 /-$ & Unknown lactone \\
\hline 37 & 26.2 & 219 & $-/ 355$ & Dihydrohelenalin isobutyrate \\
\hline 38 & 28.6 & 223 & $-/ 369$ & Helenalin tyglinate \\
\hline 39 & 34.1 & 220 & $-/ 367+$ & Dihydrohelenalin -2-methylbutyrate \\
\hline 40 & 37.4 & 229 & $-/ 371$ & Dihydrohelenalin isovalerate \\
\hline 41 & 40.1 & 227 & $-/ 371$ & Helenalin-2-methylbutyrate \\
\hline 42 & 43.5 & 219 & $-/ 369$ & Helenalin isovalerate \\
\hline 43 & 46.4 & 220 & $-/ 369$ & \\
\hline
\end{tabular}


Table 4. Determined concentrations of identified compounds in Arnica TM tincture (Boiron) (mg/100g d.w. and mg/100 mL tincture).

\begin{tabular}{|c|c|c|c|}
\hline \multirow[b]{2}{*}{ Lp. } & \multirow[b]{2}{*}{ Compound } & \multicolumn{2}{|c|}{ Arnica TM Boiron } \\
\hline & & $\begin{array}{c}\text { Amount } \\
{[\mathrm{mg} / 100 \mathrm{~g} \mathrm{~d} . w .]}\end{array}$ & $\begin{array}{c}\text { Amount } \\
{[\mathrm{mg} / 100 \mathrm{~mL} \text { tincture }]}\end{array}$ \\
\hline 1 & Isomer of caffeoylquinic acid & $41.5 \pm 1.8$ & $4.61 \pm 0.20$ \\
\hline 2 & 3,4-dihydrobenzoic acid (protocatechic acid) & $6.04 \pm 0.15$ & $0.672 \pm 0.017$ \\
\hline 3 & 5-O-caffeyloquinic acid (chlorogenic acid) & $41.2 \pm 1.1$ & $4.58 \pm 0.12$ \\
\hline 4 & Caffeic acid & $16.68 \pm 0.57$ & $1.857 \pm 0.064$ \\
\hline 5 & 1,3-di-O-caffeoylquinic acid (cynarin) & $12.82 \pm 0.39$ & $1.427 \pm 0.043$ \\
\hline 6 & Patuletin 3-O-glucoside & $7.33 \pm 0.14$ & $0.815 \pm 0.015$ \\
\hline 7 & Patuletin 3-O-glucuronide & $4.41 \pm 0.25$ & $0.491 \pm 0.028$ \\
\hline 8 & Quercetin 3-O-glucoside (isoquercetin) & $5.19 \pm 0.11$ & $0.577 \pm 0.012$ \\
\hline 9 & Quercetin 3-O-glucuronide & $6.91 \pm 0.19$ & $0.769 \pm 0.021$ \\
\hline 10 & Eupafolin 7-O-glucoside & $14.7 \pm 1.7$ & $1.64 \pm 0.18$ \\
\hline 11 & Isomer of dicaffeoylquinic acid & $55.0 \pm 2.7$ & $6.12 \pm 0.30$ \\
\hline 12 & Eupafolin 7-O-glucuronide & $7.76 \pm 0.41$ & $0.864 \pm 0.046$ \\
\hline 13 & Kaempferol 3-O-glucoside & $6.56 \pm 0.29$ & $0.730 \pm 0.032$ \\
\hline 14 & Kaempferol 3-O-glucuronide & $7.55 \pm 0.13$ & $0.840 \pm 0.014$ \\
\hline 15 & 3,5-di-O-caffeoylquinic acid & $450 \pm 13$ & $50.1 \pm 1.4$ \\
\hline 16 & 1,5-di-O-caffeoylquinic acid & $31.5 \pm 1.1$ & $3.51 \pm 0.12$ \\
\hline 17 & 4,5-di-O-caffeoylquinic acid & $6.80 \pm 0.32$ & $0.757 \pm 0.036$ \\
\hline 18 & 1-methoxyoxaloyl-3,5-di-O-caffeoylquinic acid & $33.7 \pm 1.1$ & $3.75 \pm 0.13$ \\
\hline 19 & Isomer of di-O-caffeoylquinic acid & $37.1 \pm 1.3$ & $4.13 \pm 0.15$ \\
\hline 20 & Luteolin 3'-O-glucoside & $8.69 \pm 0.23$ & $0.968 \pm 0.026$ \\
\hline 21 & Isomer of di-O-caffeoylquinic acid & $5.09 \pm 0.09$ & $0.567 \pm 0.010$ \\
\hline 22 & Kaempferol 3-O-acetylglucoside & $12.00 \pm 0.35$ & $1.335 \pm 0.039$ \\
\hline 23 & Derivative of caffeic acid & $5.35 \pm 0.23$ & $0.596 \pm 0.026$ \\
\hline 24 & Tricaffeoylquinic acid & $8.65 \pm 0.28$ & $0.962 \pm 0.031$ \\
\hline 25 & Derivative of caffeic acid & $36.1 \pm 1.7$ & $4.017 \pm 0.193$ \\
\hline 26 & Derivative of caffeic acid & $7.84 \pm 0.39$ & $0.872 \pm 0.044$ \\
\hline 27 & 6-Methoxyapigenin & $19.6 \pm 1.6$ & $2.178 \pm 0.176$ \\
\hline 28 & Apigenin & $2.30 \pm 0.15$ & $0.256 \pm 0.016$ \\
\hline 29 & Kaempferol & $0.55 \pm 0.01$ & $0.061 \pm 0.001$ \\
\hline 30 & Derivative of caffeic acid & $*$ & $*$ \\
\hline & Total flavones & $53.0 \pm 6.7$ & $5.91 \pm 0.44$ \\
\hline & Total flavonols & $42.9 \pm 3.5$ & $5.62 \pm 0.16$ \\
\hline & Total phenolic acids & $803 \pm 110$ & $88.527 \pm 2.88$ \\
\hline
\end{tabular}

*not quantitatively determined

glucoside. The above-mentioned compounds with the exception of eupafolin 7-O-glucoside have been previously identified in arnica flowers [16,17,31]. Among the free aglycones in the Arnica TM tincture, only 6-methoxyapigenin (compound 27) was recognized (Fig. 2).

For the first time, the presence of eupafolin 7$O$-glucoside (12) in Arnica montana, as well as kaempferol 3-acetylglucoside (28) and luteolin 3'$O$-glucoside (25) was indicated (Fig. 2). The last two compounds have been detected so far only in Arnica chamissonis flowers (16).

\section{Identification of caffeic acid esters}

In the studied plant material, a number of compounds with a similar UV spectrum to caffeic acid 
have been demonstrated (232, 241sh, 294sh, 322) (Table 2 and Fig. 2) (20, 21). These were compounds: 1, 15, 16, 17, 18, 19, 21, 23, 24, 25, 26 and 30. Based on the value of molecular ion at $\mathrm{m} / \mathrm{z} 603$ $[\mathrm{M}+\mathrm{H}]^{+}$in the ESI-MS spectrum, 18 was identified as 1-methoxyoxaloyl-di- $O$-caffeoylquinic acid $(20,21)$. On the basis of the presence of molecular ion $[\mathrm{M}+\mathrm{H}]^{+}$at $m / z 517$ in the ESI-MS spectra and the elution sequence (32) the structures of the following compounds were initially characterized as di- $O$-caffeoylquinic acid isomers - 3,5-di- $O$-CQA (15), 1,5-di- $O$-CQA (16), 4,5-di- $O$-CQA (17). In contrast, compound 24 based on the $m / z 679$ molecular ion $[\mathrm{M}+\mathrm{H}]^{+}$value may be a tricaffeoylquinic acid. In addition to the chlorogenic acid, the presence of the mono-caffeoylquinic isomer - compound 1 [e.g. cryptochlorogenic (4- $O$-caffeoyl) acid or neochlorogenic (3-O-caffeoyl) acid] was shown, whose molecular ion $[\mathrm{M}+\mathrm{H}]^{+}$at $\mathrm{m} / \mathrm{z} 355$, corresponds to the molecular weight of chlorogenic acid which is 5-O-caffeoylquinic acid.

HPLC analysis using the MS and DAD detectors did not reveal the presence of some of the phenolic acids identified earlier in A. montana flower, e.g. tricaffeoyl-oxaloyl-quinic acid, di- $O$-caffeoyldimethoxyoxaloyl-quinic acid, acetyl-feruloylmethoxyoxaloyl-quinic acid, di- $O$-caffeoylfumaroyl-quinic acid $(20,21)$.

The obtained separations of the majority of extract components from Arnica TM, confirm the better separation efficiency of simple phenols and polyphenols on the PFP type column, compared to C-18 (Fig. 1). The separation process on Kinetex $\mathrm{PFP}$, in comparison to Kinetex C-18, includes 5 different mechanisms of interactions for polar and nonpolar compounds, including hydrophobic interactions, ð-ð (aromatic rings), electrostatic, steric and associated with the formation of hydrogen bonds (33).

\section{Identification of triterpene lactones}

The analyses were carried out on two Kinetex C-18 columns $(2.6 \mu \mathrm{m}, 4.60 \times 100 \mathrm{~mm})$ connected in series using gradient elution according to the program III. Bergonzi et al. (34) analyzing the chemical composition of Arnica montana tincture noted the limitations of the European Pharmacopoeial method of sesquiterpene lactones determination. The method requires to carry out the complex purification step of the extract (35) prior to separation on a short HPLC column $(150 \mathrm{~mm})$. In our study, the connection in series of two columns $(2 \times 100 \mathrm{~mm})$ enabled effective separation of sesquiterpene lactones in raw arnica extract (Figure 3) in the similar time as in the analysis of the arnica flower extract preceded by its purification on a column $(13,36)$. Moreover, compared to the method used by Schmidt et al. (26) to determine sesquiterpene lactones in arnica leaves, the extended analysis time in our method enabled the separation of helenalin isobutyrate and helenalin tyglinate. As a result, 12 compounds in the Arnica TM tincture were identified based on their UV and mass spectra (32-43) as belonging to the group of sesquiterpene lactones, including esters of helenalin (compounds 37, 39, 42, 43), esters of $11,13 \alpha$-dihydrohelenalin (compounds 38, 40, 41) and acetyl-dihydrohelenalin (compound 34) $(13-15,18,28)$. In addition, based on the molecular ion at $m / z 371[\mathrm{M}+\mathrm{Na}]^{+}$in obtained ESI mass spectrum, compound $\mathbf{3 3}$ was found to be $11 \alpha, 13-$ dihydro-2-O-tigoylflorilenalin, previously identified in fresh flowers of A. montana (12). This compound, in contrary to helenalin and dihydrohelenalin classified as $10 \alpha$-methylpseudoguaianolides, belongs to another group of sesquiterpene lactones, namely 1,5-trans-guaianolides (12). Three other compounds 32, 35, 36 had UV spectra with maximum absorption in the characteristic range of $\alpha$, â-unsaturated sesquiterpene lactones (205-225 nm) (36), however their molecular weights calculated on the basis of $\mathrm{m} / \mathrm{z}$ molecular ion values, not corresponded to the molecular masses of other sesquiterpenes identified so far in the arnica flowers (12). Given the low $t_{R}$ value of helenalin $(6.7 \mathrm{~min})$ and the presence of a number of interfering compounds from the matrix, it was not possible to determine this compound in the Arnica TM tincture under described above HPLC conditions (Fig. 3). For these purposes gradient elution program has been changed in terms of its profile and decrease of elution power of used solvent

Table 5. Determined concentrations of sesquiterpene lactones, helenalin and dihydrohelenalin esters and free helenalin in Arnica TM (Boiron).

\begin{tabular}{|c|c|c|}
\hline \multicolumn{3}{|c|}{ Content of sesquiterpene lactones in ArnicaTM tincture [mg/100 g d.w.] \pm SD } \\
\hline Total & Helenalin and dihydrohelenalin esters & Helenalin \\
\hline $99.4 \pm 3.4$ & $88.2 \pm 6.4$ & $0.591 \pm 0.015$ \\
\hline
\end{tabular}


mixture - changes in concentration of $\mathrm{MeOH}$ in a mixture of $\mathrm{MeOH}: \mathrm{H}_{2} \mathrm{O}$ from proportion $50: 50 \mathrm{v} / \mathrm{v}$ to $45: 5 v / v$ (program II). Helenalin (31) was effectively separated on Kinetex C-18 columns $(2.6 \mu \mathrm{m}$ $4.60 \times 100 \mathrm{~mm}$ ) with $t_{R} 17.3 \mathrm{~min}$ (Fig. 4). The identity of the analyzed compound was confirmed by the comparison with the UV and ESI-MS spectra of the helenalin standard.

\section{Quantification of active biologically compounds from Arnica species}

The contents of the compounds are given in $\mathrm{mg}$ of the compound per $100 \mathrm{~g}$ of analyzed dried plant material, constituting the whole plant used to obtain the Arnica TM tincture calculated from the data provided by the manufacturer - Boiron (France) (Table 4 and 5). Moreover, in Table 4, the content of individual compounds in $100 \mathrm{~mL}$ of Boiron's tincture was showed. The content of individual flavonols was calculated on quercetin, flavones expressed as luteolin and caffeoylquinic acids/phenolic acids calculated as chlorogenic acid (Table 4). The content of free helenalin and other sesquiterpene lactones, including esters of helenalin and dihydrohelenalin was calculated on helenalin standard (Table 5).

\section{Flavonoids}

In terms of the dried herbal material constituting the whole A. montana plant, the estimated flavonols content was $42.9 \pm 3.5 \mathrm{mg} / 100 \mathrm{~g} \mathrm{~d}$.w. and flavones $53.0 \pm 6.7 \mathrm{mg} / 100 \mathrm{~g} \mathrm{~d} . \mathrm{w}$. (Table 4). The dominant flavonoids were determined as 6methoxyapigenin (27) $(19.6 \pm 1.6 \mathrm{mg} / 100 \mathrm{~g} \mathrm{~d}$.w.), eupafolin-7-O-glucoside $(\mathbf{1 0})(14.7 \pm 1.7 \mathrm{mg} / 100 \mathrm{~g}$ d.w.) and kaempferol-3- $O$-acetylglucoside (22) $(12.0 \pm 0.35 \mathrm{mg} / 100 \mathrm{~g} \mathrm{d.w}$.) (Table 4).

\section{Sesquiterpene lactones}

A. montana TM Boiron proved to be rich in sesquiterpene lactones $-99.4 \pm 3.4 \mathrm{mg} / 100 \mathrm{~g}$ d.w (40) (Table 5). The content of helenalin and dihydrohelenalin esters was determined as $88.2 \pm 6.4$ $\mathrm{mg} / 100 \mathrm{~g}$ d.w. and free helenalin as $0.591 \pm 0.015$ $\mathrm{mg} / 100 \mathrm{~g}$ d.w. (Table 5). The determined content of sesquiterpene lactones by us in Arnica TM tincture and whole Arnica plant may be higher because dihydrohelenalins possess weaker absorbances at the 225 $\mathrm{nm}$ wavelength. According to Perry et al. (13), this problem also applies to the European Pharmacopoeia method, and its use means that sesquiterpene lactones content in arnica samples rich in helenalin esters can be almost twice as high as their real content. To solve this problem, the authors (13) pro- posed taking into account the differences between the values of response factors (based on relative absorbance in relation to helenalin methacrylate) experimentally established for individual sesquiterpene lactones - helenalin and dihydrohydrohelenalin esters. Because the Arnica TM contains several sesquiterpene lactones with the unknown structure the use of the method developed by Perry et al. (13) was impossible.

\section{Phenolic acids}

Among the identified compounds, the A. montana TM tincture chemical composition is significantly dominated by 3,5-di- $O$-caffeoylquinic acid $(50.1 \pm 1.4 \mathrm{mg} / 100 \mathrm{~mL}$, which is equal to $450 \pm 13$ $\mathrm{mg} / 100 \mathrm{~g} \mathrm{~d} . \mathrm{w}$.). Another dominating compound is chlorogenic acid $(4.58 \pm 0.12 \mathrm{mg} / 100 \mathrm{~mL})$. In addition, at a concentration of about $4 \mathrm{mg} / 100 \mathrm{~mL}$ each, numerous caffeic acid derivatives are also present (Table 4). The content of compounds belonging to phenolics in the starting plant material for the production of Arnica TM was characterized as $803 \pm$ $110 \mathrm{mg} / 100 \mathrm{~g} \mathrm{d.w.} \mathrm{(Table} \mathrm{4).}$

\section{CONCLUSIONS}

The analysis of the chemical composition of the tincture from Arnica montana whole plant was conducted for the first time, showing mainly quantitative differences between the whole Arnica plant and Arnica flowers (13, 38-39).

The tincture of Arnica TM (Boiron) is a rich source of caffeic acid derivatives (Table 4), especially $C Q A s$ - mono- and di- $O$-caffeoylquinic acids. Among them 3,5-di- $O$-caffeoylquinic acid (compound 15) is a dominating compound and presenting in higher concentration than it was shown in Arnica flowers (38-39).

On the other hand, the whole $A$. montana plant contains a smaller amount of sesquiterpene lactones, estimated at about $0.1 \%(99.4 \pm 3.4 \mathrm{mg} / 100 \mathrm{~g}$ of dry matter), compared to at least $0.4 \%$ in the flowers of Arnica required by the European Pharmacopoeia (35). However, the determined content is significantly higher comparing to the content of sesquiterpene lactones, described in the monograph of Arnica montana whole plant in French Pharmacopoeia (at least $0.01 \%$ calculated on dihydrohelenalin tiglinate) (40). Compared to the chemical composition of arnica flowers, the whole plant also contains a smaller amount of flavonoids (about $0.1 \%$ ) compared to the Polish Pharmacopoeia V norm (at least $0.4 \%$ of flavonoids expressed as quercetin) (41). 
The high content of caffeic acid derivatives, which have hepatoprotective (5-CQA, cynarin), antiinflammatory and antioxidant activity confirms the use of Arnica TM as an anti-inflammatory drug. Although more research is needed to determine the relationship between activity and the chemical structure of various $C Q A s$ derivatives.

\section{Conflict of interest}

The authors declare no conflicts of interest.

\section{REFERENCES}

1. Schulz V., Hansel R., Tyler V.E.: Rational phytotherapy. A physicians guide to herbal medicine, Springer, Berlin 2001.

2. Mills S., Bone K.: The essential guide to herbal safety, Elsevier, Missouri 2005.

3. Edwards S.E., da Costa Rocha I., Willamson E.M., Heinrich M.: Phytopharmacy an evidence-based guide to herbal medicinal products, Wiley Blackwell, Chichester 2015.

4. Leung A.Y.F.S.: Encyclopedia of common natural ingrediens used in food,drugs and cosmetics, Wiley and Sons, New Jersey 2003.

5. Hall I.H., Lee K.H.: J. Pharm. Sci. 68, 537 (1979).

6. Hall I.H., Starnes C.O., Lee K.H., Waddell T.G.: J. Pharm. Sci. 69, 537 (1980).

7. Jäger C., Hrenn A., Zwingmann J., Suter A., Merfort I.: Planta Med. 75, 1319 (2009).

8. Klass C.A., Wagner G., Laufer S., Sosa S., Loggia R.D. et al.: Planta Med. 68, 385 (2002).

9. Lyss G., Schmidt T.J., Merfort I., Pahl H.L.: Biol. Chem. 378, 951 (1997).

10. Merfort I.: Forsch Komplementarmed Klass Naturheilkd. 10, 45 (2003).

11. Tornhamre S., Schmidt T.J., Nasman-Glaser B., Ericsson I., Lindgren J.A.: Biochem. Pharmacol. 62, 903 (2001).

12. Kos O., Lindenmeyer M.T., Tubaro A., Sosa S., Merfort I.: Planta Med. 71, 1044 (2005).

13. Perry N.B., Burgess E.J., Rodríguez Guitián M.A., Franco R.R., Mosquera E.L. et al.: Planta Med. 75, 660 (2009).

14. Spitaler R., Schlorhaufer P.D., Ellmerer E.P., Merfort I., Bortenschlager S. et al.: Phytochemistry 67, 409 (2006).

15. Zheleva-Dimitrova D.Z., Balabanova V., Gevrenova R., Doichinova I., Vitkova A.: Pharmacogn. Mag. 11 (Suppl 4), 538 (2015).

16. Merfort I., Wendisch D.: Planta Med. 58, 355 (1992).
17. Merfort I., Wendisch D.: Planta Med. 53, 434 (1987).

18. Stefanache C.P., Bujor O.C., Necula R., Grigoras V., Mardari C. et al.: Planta Med. 82 (Supp 01), S381 (2016).

19. Balabanova V.C.R.: Acad. Bulg. Sci. 66, 1547 (2013).

20. Merfort I.: Phytochemistry 31, 2111 (1992).

21. Jaiswal R. Kuhnert N.: Food Funct. 2, 63 (2011).

22. Neelakandan M., Vasudevan K., Senthamaraikannan K., Manoharan S.: Int. J. Res. Pharm. Sci. 8, 28 (2017).

23. Liang N., Kitts D.D.: Nutrients 8, 125 (2015).

24. Chen W., Wu L.: Int. J. Clin. Exp. Pathol. 7, 8797 (2014).

25. Liu C., Zhang Y., Dai B., Ma Y., Zhang Q. et al.: Mol. Med. Rep. 16, 1369 (2017).

26. Schmidt T.J., Bomme U., Alfermann A.W.: Planta Med. 64, 268 (1998).

27. Danila D., Stefanache C.P., Bujor O.C., Necula R., Tanase C. et al.: Planta Med. 82, 1 (2016).

28. Hostettmann K., Chen S., Marston A., H. Handbook of Chemical and Biological Plant Analytical Methods, Wiley, Chichester, 2014.

29. Food and Drug Administration, Reviewer Guidance, Validation of Chromatographic Methods, 1994, http://www.fda.gov/downloads/Drugs/Guidances/UCM134409.pdf (accessed on: 20.05.2019).

30. Merfort I.,Wendisch D.: Planta Med. 16, 98 (1987).

31. Mabry T.J., Markham K.R., Thomas M.B., The Systematic Identification of Flavonoids, Springer-Verlag, Nowy Jork 1970.

32. Lin L-Z., Harnly J.M.: J. Agric. Food Chem. 56, 10105 (2008).

33. Kula M., Głód D., Krauze-Baranowska M.: J. Pharm. Biomed. Anal. 121, 99 (2016).

34. Bergonzi M.C., Bilia A.R., Casiraghi A., Cilurzo F., Minghetti P. et al.: Pharmazie 60, 36 (2005).

35. European Pharmacopoeia 9, Strasbourg: Council of Europe (2017).

36. Douglas J.A., Smallfield B.M., Burgess E.J., Perry N.B., Anderson R.E. et al.: Planta Med 70, 166 (2004).

37. Sülsen V.P., Martino V.S.: Sesquiterpene Lactones: Advances in their Chemistry and Biological Aspects, Springer 2018.

38. Ganzera M., Egger C., Zidorn C., Stuppner H.: Anal. Chim. Acta. 614, 196 (2018).

39. Zhang J.Y., Wang Z.J., Li Y., Liu Y., Cai W. et al.: Talanta 147, 16 (2006). 
40. Arnica montana (Whole Plant) for Homeopathic Preparations]. In: Pharmacopee Francaise 11, ANSM (2008) https://www.ansm.sante. fr/var/ansm_site/storage/original/applica- tion/49916892102e6cd5ec523a5546f36a99.pdf (accessed on 4.09.2019).

41. Farmakopea Polska V, Warszawa: URPL (1999).

Received: 24.05 .2019 